\title{
VIDA, ESTUDO E TRABALHO: DISCUTINDO AS TRAJETÓRIAS DOS JOVENS BRASILEIROS A PARTIR DA TEORIA DE INSERÇÃO PROFISSIONAL FRANCESA
}

\author{
LIFE, STUDY AND WORK: DISCUSSING BRAZILIAN YOUNG \\ TRAJECTORIES FROM THE FRENCH PROFESSIONAL INSERTION \\ THEORY
}

\author{
Jhony Pereira Moraes \\ UFRGS \\ jhonymoraes@hotmail.com.br \\ Sidinei Rocha-De-Oliveira \\ UFRGS \\ sidroliveira@hotmail.com \\ Arthur Gehrke Martins Andrade \\ UFRGS \\ arthur_gma@hotmail.com
}

Submissão: $17 / 07 / 2018$

Aprovação: 24/01/2020

\begin{abstract}
RESUMO
Este estudo objetiva realizar uma aproximação entre a teoria de inserção profissional francesa e a juventude brasileira. Os pontos centrais de análise são a vida, o estudo e o trabalho, uma vez que a inserção profissional francesa considera os aspectos individuais, institucionais e sócio-históricos de um grupo social, sendo extensiva a diferentes contextos sociais. O estreitamento dessa teoria com a juventude brasileira é evidenciado pelo cenário formado por jovens franceses com elevada qualificação e grandes dificuldades de inserção no mercado - com atenção aos casos de desemprego e disposição de relações de trabalho precarizadas - algo semelhante ao que vem acontecendo com os jovens brasileiros nos últimos anos, apesar da expansão do ensino superior (considerando a influência de políticas públicas de acesso e programas de financiamento da educação superior).
\end{abstract}

Palavras-chave: Inserção profissional. Juventude brasileira. Mercado de trabalho.

\begin{abstract}
This study aims to achieve an approximation between the theory of French professional insertion and the Brazilian youth. The central points of analysis are life, study and work, since the French professional insertion considers the individual, institutional and sociohistorical aspects of a social group, being extended to different social contexts. The narrowing of this theory with the Brazilian youth is evidenced by the scenario formed by highly qualified young people and great difficulties of insertion in the market - with
\end{abstract}


attention to the cases of unemployment and the provision of precarious working relations something similar to what has been happening with young people Brazilians in recent years, despite the expansion of higher education (considering the influence of public access policies and higher education funding programs).

Keywords: Professional insertion. Brazilian youth. Job market.

\section{INTRODUÇÃO}

Com as transformações socioeconômicas ocorridas ao longo das últimas décadas no Brasil, observa-se a extensão do tempo de estudos, notadamente pela ampliação do ingresso no ensino superior (ROCHA-DE-OLIVEIRA; PICCININI, 2012a). Com isso, percebe-se um fenômeno ocorrido em outros países, uma extensão na fase educacional quando relacionada à entrada no mercado de trabalho, apontado por Galland (2000) ao analisar a situação da França no final do século XX.

A conclusão dos estudos é elevada como prioridade, enquanto isso, a permanência na casa dos pais é crescente. Na França, por exemplo, essa estadia ultrapassa os 25 anos de idade. Galland (2000) argumenta que a juventude de hoje difere daquela de anos passados. A saída da casa dos pais, o acesso ao emprego e a constituição de família aconteciam em um espaço de tempo menor, sendo a independência conquistada mais rapidamente. Observa-se que a independência dos jovens está cada vez mais tardia.

Tartuce (2007) evidencia que a crise da escola e do mercado de trabalho na década de 1970 fragmentou a centralidade do trabalho na vida da população, dispersando a linearidade do ciclo de vida (formação, emprego, família). Ademais, essa transformação colaborou para a redução da vida ativa no trabalho, para o aumento dos anos de formação (sendo a massificação do ensino uma das causas), para a manifestação de relações precárias de trabalho e desemprego (TARTUCE, 2007). Corrochano (2013) afirma que no Brasil a situação dos trabalhadores, não somente os jovens, aproxima-se mais da instabilidade. A frágil proteção do trabalhador e a desatenção à população desempregada contribuem não somente para a precariedade dos vínculos de trabalho como também para o desempenho de trajetórias não-lineares.

No ano de 1980, ganham destaque estudos sobre trajetórias de estudantes que trabalham e a importância do trabalho como contribuição para a formação. Nesse contexto, ressalta-se o uso do trabalho como uma fonte de aquisições pessoais que superam a barreira da sobrevivência e a manutenção do lar pelos jovens trabalhadores; assim também sendo uma fonte de financiamento dos estudos. Contudo, a crise do emprego em 1990 colaborou para a queda dos postos de trabalho, principalmente para os provedores do sustento familiar. Nesta mesma década ampliam-se os estudos sobre inserção profissional dos jovens brasileiros, educação e qualificação. Desenvolvem-se análises mais profundas sobre a relação com o trabalho e o seu significado para esses jovens, sobre desemprego e o processo de transição escola-mercado de trabalho (CORROCHANO, 2013).

Diante disso, este estudo buscar trazer um olhar teórico sobre o processo de inserção profissional e o jovem brasileiro, adotando-se aqui a vertente francesa de inserção, uma vez que a mesma contempla diferentes dimensões: sócio-histórica, individual e institucional (ROCHA-DE-OLIVEIRA, 2011).

\section{JUVENTUDE E TRABALHO E OS ANTECEDENTES DA DISCUSSÃO SOBRE INSERÇÃO PROFISSIONAL}


Diferentes concepções foram apresentadas ao longo do tempo para identificar o processo de ingresso na vida profissional, tais como entrada na vida ativa, entrada no trabalho e inserção profissional. Nesse sentido, o conceito de entrada na vida ativa representa a "passagem instantânea e breve da formação inicial para o emprego ou o desemprego" (VERNIÈRES, 1993, p. 93, apud ALVES, 2007). Por outro lado, na mesma época, a literatura anglo-saxônica apresentou a expressão entrada no trabalho, significando um ambiente de acolhimento, observado que a transição formação-mercado de trabalho suscitava uma situação de estresse e angústia, como também de ausência de orientação vocacional (ALVES, 2007).

O emprego da expressão inserção profissional teve importância maior em meio à crescente dificuldade de entrada no mercado pelos jovens franceses em transição universitária, sendo que seu uso foi visto inicialmente em textos legislativos da década de 1970 (DUBAR, 2001). Portanto, passou a expressar um processo complexo e longo de ingresso profissional, em relação ao entendimento inicial de um fato instantâneo (ALVES, 2007). A relevância do tema no contexto francês deriva da preocupação do governo a respeito da relação formação-emprego, focalizando os casos de desemprego juvenil (ROCHA-DEOLIVEIRA; PICCININI, 2012a). A preocupação do Estado francês com a inserção dos jovens do país foi potencializada no ano de 1980, passando a considerá-la como uma demanda social, discorrendo-se sobre desemprego, exclusão juvenil e sistema de ensino associado ao mercado de trabalho (ROCHA-DE-OLIVEIRA; PICCININI, 2012a). Corroborando, Dubar (2001) suscita que a transição escola-mercado de trabalho eclodiu uma transformação histórica na sociedade francesa, reforçada e incentivada pela legislação vigente no século XIX.

O período de inserção profissional, conforme Dubar (2001) marcou uma época importante para a vida dos jovens franceses. Essa fase de vida é vista como intermediária entre adolescência e vida adulta e carrega consigo algumas indecisões em relação ao futuro: busca-se o desenvolvimento por meio da progressão na carreira, pelos estudos etc.; em contrapartida, os jovens pensam em casamento, filhos e em ter sua casa própria. Por esse motivo, por mais que a inserção profissional seja entendida como um problema social considera-se parte da construção histórica de tal sociedade.

Nesse país, como agente de monitoramento da inserção profissional dos jovens fundou-se o Centre d'Études et Recherches sur les Qualifications - o CÉREQ - onde os estudos "consideram o processo de inserção como um caminho marcado por períodos de inatividade, desemprego e emprego, focando suas análises nos montantes salariais e em movimentações nas quais os indivíduos aparecem como números" (ROCHA-DEOLIVEIRA; PICCININI, 2012a, p. 66).

Vincens (1981, apud ALVES, 2007) traz a primeira conceituação de inserção profissional. Para o autor, essa expressão indica a procura de emprego, onde o indivíduo (ou agente) possui informações limitadas sobre a oportunidade; sendo que essa procura é uma etapa importante e faz parte do cotidiano do profissional. Segundo Vincens, o indivíduo é estratégico e possui comportamento racional. $\mathrm{O}$ autor afirma ainda que o processo de inserção profissional pode não ter sua conclusão com o primeiro emprego, visto que a finalização desse processo ocorre por meio de três fatores: a existência de um emprego durável; a ausência do sentimento de abandono voluntário ao emprego; e a descontinuidade do tempo de busca de novas oportunidades ou de dedicação aos estudos com o objetivo de troca de emprego ou de atuação em outra atividade profissional (VINCENS, 1981, apud ALVES, 2007).

O estudo da inserção profissional no Brasil teve início na década de 1970, com atenção à camada estudantil de classe média. Foi apenas com a expansão do ensino público 
e de ampliação das condições de consumo, emprego e de acesso ao crédito que a população de trabalhadores (apenas) e daqueles que estudam e trabalham foram inseridas nas pesquisas sobre inserção profissional (CORROCHANO, 2013). Essas análises têm como ponto de partida o trabalho como um aspecto central para o desenvolvimento da juventude brasileira. A sua exposição às precárias condições do mercado desperta novos sentidos ao trabalho, refletindo no contexto social e na trajetória vivenciados por aqueles jovens (CORROCHANO, 2013).

Em nosso país, nota-se haver um aumento nos estudos dedicados a analisar a inserção profissional de jovens, todavia, carecemos de estudos voltados a desenvolver o conceito de inserção profissional, "que para amadurecimento da temática e melhor delimitação dos campos de pesquisa é fundamental que se façam reflexões conceituais sobre o tema" (ROCHA-DE-OLIVEIRA; PICCININI, 2012a, p. 64). Conforme Volkmer Martins (2016) os estudos acerca do tema inserção profissional se dispersam em áreas como Educação e Economia, para além da Administração. Geralmente, recaem em estudos empíricos, situando problemas de exclusão. A autora destaca que textos como de "Franzoi (2006; 2011), Bitencourt, Piccinini, Rocha-de-Oliveira e Gallon (2012), e de Rocha-deOliveira e Piccinini (2012b), buscam desenvolver e avançar teoricamente o conceito" (VOLKMER MARTINS, 2016, p. 77).

O cenário brasileiro contrasta com a realidade apresentada na teoria sobre o processo de inserção profissional. No entendimento de Corrochano (2013), a transição escolamercado de trabalho não é perfeita e instantânea. Perpassa pelo ingresso precoce no mercado e pela superposição do trabalho à educação. Soma-se ainda o fortalecimento dos vínculos não-formais como meios de sobrevivência, principalmente à população jovem, que possui o trabalho como base de seu crescimento.

Lemos, Dubeux e Pinto (2009) sinalizam que a qualificação profissional se mostra como um desafio para aqueles que visam o ingresso no mercado de trabalho. Essa questão reflete o debate internacional sobre a crise do emprego, que tem a qualificação como estratégia de enfrentamento do desemprego em diferentes países, florescendo uma lógica brasileira de valorização da formação para o trabalho. Diante desse cenário, agrega-se maior valor à educação, servindo de ponte de possibilidades para a inserção profissional dos jovens, com o intuito de garantir maior empregabilidade, indo além da contribuição para o desenvolvimento econômico. Em contrapartida, a existência de profissionais que ocupam posições abaixo de suas qualificações é expressiva. Conforme Lemos, Dubeux e Pinto (2009) esse problema é vivenciado, em grande parte, pelos profissionais advindos de classes sociais mais carentes, mesmo possuindo formação elevada (ensino superior completo), sendo que isso é 17 vezes maior em comparação às classes sociais mais abastadas, em mesmo nível educacional.

Oliveira e Sousa (2013) observaram o aumento do exército de reserva no mercado de trabalho. Para os autores o aumento da produtividade das pessoas empregadas estimula a expansão desse exército, que tenta angariar uma oportunidade às custas, geralmente, da situação de desemprego de outro profissional. No Brasil, o contexto juvenil de exército de reserva é o mais agravante e altamente competitivo, algo que é justificado, principalmente, pelo crescimento da população jovem brasileira, pela elevação da produtividade, dispensando a contratação de novos trabalhadores; e pela exigência de maior escolaridade, sendo o jovem pobre o mais afetado. Segundo informações do Fundo de População das Nações Unidas, no ano de 2010, estimou-se uma população jovem próxima a 1,5 bilhão de indivíduos entre 15 e 24 anos (OLIVEIRA; SOUSA, 2013). Os autores argumentam, sobretudo, que esse excedente de mão de obra no extrato jovem da população brasileira sob condições perversas de competitividade - incita a ocupação de vagas de baixa 
relevância nas organizações.

Dois fatores impactam essa realidade: a tecnologia e a globalização econômica. Deles, derivam exigências elevadas sobre a escolaridade dos funcionários, quer para a entrada, quer para a permanência no emprego (OLIVEIRA; SOUSA, 2013). Ademais, nos extratos menos escolarizados são comuns índices de desemprego e de exclusão social maiores. Diante disso, tais desigualdades sociais afetam, especialmente, o jovem pobre (OLIVEIRA; SOUSA, 2013). A cobrança brasileira por educação com vistas à inserção profissional se distingue do cenário europeu, que predispõe de escolaridade básica para os jovens, contudo, enfrenta o desemprego (OLIVEIRA; SOUSA, 2013). Os jovens profissionais brasileiros respondem ao problema de inserção através da busca de qualificação e educação. Em se tratando de educação, a legislação educacional brasileira segue recomendações internacionais em prol da democratização da educação, ampliando a cobertura de oferta obrigatória do ensino a fim de agir sobre o desemprego (OLIVEIRA; SOUSA, 2013).

\section{A INSERÇÃO PROFISSIONAL FRANCESA E SUAS CARACTERÍSTICAS}

Conceitualmente, Rocha-de-Oliveira e Piccinini (2012b) afirmam que a inserção profissional representa um processo individual, ao mesmo tempo coletivo, histórico e socialmente inscrito. Os autores explicam essa definição:

Individual porque diz respeito à experiência vivenciada por cada sujeito na esfera do trabalho, suas escolhas profissionais e expectativas de carreira. É um processo coletivo por ser vivenciado de maneira semelhante por uma mesma geração, ou no interior de grupos profissionais. É histórico, pois se desenvolve ao longo de um período da vida do sujeito, sob a influência de elementos que marcam determinado momento no tempo e no espaço, como políticas públicas, mercado de trabalho, organização do sistema de ensino e políticas de recursos humanos e os pontos de vista 'empresariais' sobre as relações entre educação e trabalho. Está inscrito em um dado contexto socioeconômico e cultural, em que, além dos elementos institucionais, há influência das construções e das representações sociais que os indivíduos desenvolvem em relação a esta inserção profissional (ROCHA-DE- OLIVEIRA; PICCININI, 2012b, p. 49).

A aproximação entre a teoria de inserção francesa e a juventude brasileira se justifica através da característica dessa teoria em analisar os elementos individuais, institucionais e sócio-históricos para a compreensão do processo de inserção vivenciado pelos jovens. Nesse sentido, pode-se entender por elementos individuais a origem familiar do indivíduo, abordando sua etnia, a escolaridade dos progenitores e os valores para o trabalho; as experiências e expectativas com o trabalho e as técnicas de inserção profissional praticadas por esses jovens. Na outra dimensão analisada (os fatores institucionais) debruca-se no entendimento de leis e normativas, das relações de trabalho, políticas de inserção e de gestão de pessoas - tanto em âmbito público ou privado - e das novas naturezas de contratos de trabalho (CORDEIRO, 2002; ROCHA-DE-OLIVEIRA; PICCININI, 2012b). Na esfera sócio-histórica analisa-se a estrutura demográfica e ocupacional, a conjuntura econômica, os níveis de formação da mão-de-obra e o desenvolvimento tecnológico e industrial (ROCHA-DE-OLIVEIRA, 2011).

Segundo Volkmer Martins (2016), uma grande contribuição desse modelo de inserção é que o mesmo resulta de complexas interações, justificando a necessidade de se observar diferentes ambientes, seja em uma escala local, regional, seja nacional, de forma que se possa visualizar as interrelações produzidas nesses ambientes entre os sistemas de ensino, as relações de trabalho (trabalho e sistema de produção) e as relações industriais. 
Cordeiro (2002) corrobora ao suscitar duas maneiras de inserção profissional: a qualificante e a não-qualificante. A primeira visa a valorização do trabalhador, onde as organizações elaboram políticas de proteção, projetam progressões de carreira, proporcionam condições de trabalho satisfatórias, desenvolvem competências individuais e do coletivo; como também há estabilidade contratual. Por outro lado, a inserção nãoqualificante é caracterizada por contratos de trabalho e políticas de gestão de pessoas e de carreira fragilizados (CORDEIRO, 2002).

Rocha-de-Oliveira e Piccinini (2012a) evidenciam que a inserção profissional dos jovens possui três características: a posse de um diploma - que o difere socialmente -, a adaptação ao mercado de trabalho, perpassando a capacitação, o auxílio financeiro antes e durante a adaptação e o primeiro emprego, sendo responsável o setor público pelo jovem e sua família no processo de inserção, ausentado as organizações desse compromisso. Por fim, a ausência de experiências profissionais impacta negativamente o ingresso do jovem no mercado de trabalho.

Para Dubar (2001) a posse de um diploma não serve mais como um objeto de destaque ou de progressão profissional, pois desde 1970 as organizações buscam a sintonia entre o título e as competências individuais do trabalhador, tais como responsabilidade, compromisso, experiências e qualidade. Já Lemos, Neves e Rodrigues (2013) explicam através de Bourdieu (que analisou a França de 1970) a existência de três capitais no processo de inserção: econômico, cultural e social. O capital econômico representa os bens e as finanças do indivíduo; o capital cultural envolve as novas culturas, os idiomas apreendidos e o diploma universitário; e o capital social refere-se às redes de relacionamento contruídas.

Desse modo, é pertinente pensar os jovens brasileiros em transição para o mercado de trabalho em relação à abordagem francesa de inserção profissional, pois essa abordagem abrange diferentes aspectos que circundam a realidade social, histórica e econômica do jovem podendo-se, assim, compreender as particularidades de sua inserção no trabalho, como também os aspectos institucionais que circunscrevem esse jovem.

Indo além, a inserção profissional é considerada um problema social, não- linear e não padronizado, e simbólico. Estrutura-se nas vivências familiares e relacionais em um contexto determinado. Ou seja, trata-se de um processo multifacetado, composto por elementos materiais e simbólicos, que sofre a interferência de aspectos individuais, institucionais e contextuais (ROCHA-DE- OLIVEIRA; PICCININI, 2012a; VOLKMER MARTINS, 2016).

Em relação a não linearidade da inserção, Tartuce (2007) salienta que a posição do indivíduo na estrutura social detém forte influência, visto que para aqueles situados mais acima na pirâmidade social há um equilíbrio e melhores resultados no processo de inserção, enquanto para aqueles situados mais abaixo prevalecem períodos maiores de desemprego e precariedade. Isto é, Tartuce (2007) afirma que os contextos socioeconômicos e socioculturais influenciam o ciclo de vida e a transição do jovem trabalhador. Portanto, a juventude é considerada como um "grupo diverso, ou múltiplas juventudes que sofrem influência do contexto histórico em que cresceram" (ROCHA-DE-OLIVEIRA; PICCININI, 2012a, p. 69). Elas se diferem nos "modos de pensar, de agir e de viver o processo de passagem à vida adulta e que, por consequência, vivem modos distintos de inserção profissional" (ROCHA-DE-OLIVEIRA; PICCININI, 2012a, p. 70).

Em contrapartida, a vertente econômica da inserção profissional francesa expressa que o jovem destina parte de seu tempo na busca por oportunidades remuneradas, diminuindo seus períodos de lazer, estudo e trabalho não remunerado. Oscilações de emprego, desemprego e estudo também se fazem presentes, os quais são amenizados no 
momento em que o jovem encontra o emprego desejado. Assim, o início da inserção profissional pelo viés econômico inicia pela busca do emprego, e a automanutenção no mercado e a estabilidade financeira o seu fim. Considera-se aqui somente aqueles indivíduos que estão nunca participaram da população ativa de trabalhadores (ROCHA-DEOLIVEIRA; PICCININI, 2012a).

Por fim, a inserção profissional francesa apresenta o déclassement, ou seja, o possível rebaixamento social do trabalhador. Conforme Volkmer Martins (2016, p. 79), o déclassement se refere ao

[...] rebaixamento intergeracional (quando os filhos se encontram numa situação menos favorável que os pais), o rebaixamento de diplomados (quando o diploma ocupa uma vaga de emprego inferior à sua qualificação) e o [...] rebaixamento durante o ciclo de vida (quando um acontecimento abrupto provoca uma degradação das condições de vida).

Na perspectiva de Peugny (2014, p. 39), que estudou o fenômeno na França, “o argumento da alta do rebaixamento social desde o fim dos anos 1970 conduz à precarização crescente das condições de vida de diversas parcelas da população", assim "os debates sobre o rebaixamento surgem para questionar a posição das classes médias no espaço social, as quais, por sua vez, estariam desestabilizadas" (PEUGNY, 2014, p. 40).

Para Peugny (2014), o jovem, independente de classe social, busca no diploma sua fonte de prosperidade, contudo, a autora ressalta que ele "não oferece uma proteção absoluta contra o rebaixamento, mesmo se os mais diplomados são evidentemente aqueles com mais chances de se recolocar na sequência" (PEUGNY, 2014, p. 84). Diante disso, a autora diz que é na colocação profissional que as diferenças de rebaixamento são constatadas, independente de os jovens serem oriundos de pais operários ou executivos.

\section{A REALIDADE DO TRABALHO BRASILEIRO NO CONTEXTO DE INSERÇÃO PROFISSIONAL}

De início é interessante citarmos o questionamento de Comin $(2015$, p. 368): “o processo de desenvolvimento econômico amplia ou reduz as desigualdades de renda entre os indivíduos?".

Apesar de o país apresentar ao longo de sua história diferentes oscilações econômicas, é fato que o desenvolvimento abriu disparidades de renda, e de forma ampliada, desigualdades sociais e culturais. Com os avanços da industrialização nos centros urbanos e a ampliação do campo dos serviços, o conhecido Brasil da agricultura cedeu, em grande parte, ao movimento das indústrias, as quais pressionaram para a reconfiguração das formas de trabalho e mobilizaram uma reorganização social, mais especificamente uma desestabilização do trabalho nas famílias rurais.

A necessidade por trabalho e a busca por melhores condições de vida incentivaram a saída do meio rural para a vida nos conglomerados urbanos. A esse movimento deficiências demográficas foram percebidas, tais como a pouca ou nenhuma formação escolar, denominada "massa marginal" (COMIN, 2015, p. 371) e a escassez de recursos. Todavia, essa migração dotou-se de uma realidade precária: esses trabalhadores constituíram "estratos sociais com renda muito baixa, excluídos da proteção social e no mercado de trabalho" (COMIN, 2015, p. 371). Em contraste

A enorme escassez relativa de força de trabalho qualificada garantiu aos estratos mais escolarizados as melhores posições no mercado de trabalho e prêmios salariais extremamente elevados, além de benefícios típicos dos Estados de bemestar social, como cobertura previdenciária, crédito habitacional subsidiado e sistemas de saúde subvencionados pelas empresas (COMIN, 2015, p. 371). 
Mediante o cenário de marginalização social do país proveniente da nova dinâmica de trabalho e do reordenamento espacial e ocupacional, vê-se que o processo de socialização se estruturou com fendas profundas em desigualdades. O crescimento da sociedade denota uma base econômica, entretanto, a manutenção do crescimento evidencia uma série de aspectos que necessitam de equilíbrio para subsidiar a economia. Contudo, a aproximação ao equilíbrio é tangente, pois as transformações que se deram culminaram em segregações sócioespaciais que reforçaram as desigualdades, tais como as desigualdades de classe, de acesso ao emprego, de acesso à Educação; e as discriminações de raça e gênero dentro e fora do trabalho.

Com a baixa da dinâmica industrial em 1980 e seu aprofundamento em 1990, percebeu-se uma deterioração do mercado de trabalho, ressaltando a informalidade dos vínculos, o desemprego e a desigualdade de renda. Essas e outras desigualdades estão imbuídas, sobretudo, em diferenças nos direitos trabalhistas e sociais, que "provém da seletividade com que a legislação trabalhista e os direitos sociais foram aplicados pelo Estado brasileiro aos diversos segmentos sócio- ocupacionais" (COMIN, 2015, p. 385). Com essa segregação ocupacional notou-se o aumento do trabalhador assalariado e a categorização profissional, ou mais especificamente, o reconhecimento legal de algumas profissões.

A existência de nichos ocupacionais reforça o desequilíbrio social na esfera do trabalho. Partindo das ocupações menos às mais qualificadas, observa-se cada vez mais uma redução do trabalho manual qualificado e uma proliferação de aparatos tecnológicos nas operações fabris e em outros segmentos do mercado. Por outro lado, é evidente o crescimento no número de profissionais com alta qualificação voltados à ciência, tecnologia e aos negócios, como decorrência da expansão do ensino superior nos últimos anos. Todavia, ocupações demandantes de trabalho manual menos qualificado se alastram, beneficiam os trabalhadores menos qualificados com as oportunidades e os agregam baixa remuneração. Diante disso, as desigualdades que se apresentam não são reduzidas, pois "continuará ainda dependendo do encolhimento dos estratos manuais de baixa qualificação" (COMIN, 2015, p. 393).

Conforme Guimarães, Barone e Brito (2015) presencia-se uma mercantilização do mercado de trabalho, em que se omite a sua formação complexa e se potencializa uma lógica de compradores e vendedores de trabalho. Porém, a ideia de oferta efetiva de trabalho esconde uma luta pela sobrevivência no mercado, influenciada por diferentes variáveis:

Características individuais: idade e escolaridade (e a maior ou menor senioridade e experiência a elas associadas, atributos com elevado valor de mercado); ou sexo e condição racial (atributos que não deveriam ter valor de mercado, muito embora o tenham); ou posição na família (e as responsabilidades de provimento da sobrevivência de dependentes, as quais, sendo socialmente esperadas, constrangem os indivíduos à ida ao mercado de trabalho);

Características do grupo domiciliar (tamanho e peso relativo dos que nele são econômica e socialmente dependentes) e que determinam a maior ou menor urgência do rendimento a ser obtido no mercado;

Contextos em que se vive e se compete (se urbano ou rural; e em que região do país), que sinalizam para a maior ou menor atratividade do mercado em que se está a ingressar (GUIMARÃES; BARONE; BRITO, 2015, p. 397).

Nesse cenário, a heterogeneidade e o engajamento no mercado de trabalho obtiveram novas narrativas a partir dos anos 2000. Enquadradas num ambiente de retração da população assalariada formal e o crescimento do desemprego (sob uma pluralidade de 
formas e oculto em ocupações precárias; e diante da ausência de políticas assistenciais mínimas de acompanhamento do trabalhador desempregado), nota-se que as relações de emprego se dão muito mais por diferenças sociais significativas do que pela natureza do trabalho ou pela ocupação ou atividade profissional (GUIMARÃES; BARONE; BRITO, 2015).

Arretche (2015) corrobora ao relacionar as desigualdades de renda com a cor e o gênero; às desigualdades educacionais; e ao acesso a serviços básicos. A autora, no campo da cor (ou raça ou etnia) e do gênero, afirma que "entre os indivíduos extremamente pobres, a desigualdade de renda por gênero e cor aumentou no mesmo contexto em que a desigualdade entre faixas de renda diminuiu", contudo, foram os homens brancos situados nesse nível social que se beneficiaram da melhoria na renda. Segundo Arretche, o salário mínimo neutraliza as desigualdades de gênero e raça na população pobre. A política do salário mínimo contribuiu para eliminar tais desigualdades entre os mais pobres pela proteção àqueles que se apresentam muito mais pobres nesse segmento. Porém, mulheres e negros sofrem com seus rendimentos quando excluídos dessa política.

Quanto às desigualdades educacionais, Arretche (2015) levanta a importância da política educacional no impacto dos níveis salariais e para a mobilidade social do trabalhador. O acesso ao ensino e a extensão do tempo de estudo são fundamentais para a redução gradual das desigualdades de renda. A autora lamenta que a massificação do ensino em nível básico tenha ocorrido tardiamente, mesmo em comparação a países latinos com índices de desenvolvimento econômico inferiores. Em relação às desigualdades no acesso a serviços básicos, Arretche (2015) salienta a conversão dos serviços de estrutura em ativos sociais capazes de garantir condições de saúde e saída da pobreza. A ausência múltipla de serviços básicos sistematiza um amplo conjunto de desvantagens principalmente em regiões que concentram grande contingente de domicílios mais pobres, onde quanto mais baixa a renda, menor a cobertura de serviços.

\section{CONSIDERAÇÕES FINAIS: PROPOSTA DE ESTUDOS FUTUROS}

Este estudo teve por objetivo fazer uma aproximação entre a teoria de inserção profissional francesa e a juventude brasileira. Os pontos centrais de análise são a vida, o estudo e o trabalho, uma vez que a inserção profissional francesa considera os aspectos individuais, institucionais e sócio-históricos de um grupo social, sendo extensiva a diferentes contextos sociais.

O estreitamento dessa teoria com a juventude brasileira é evidenciado pelo cenário formado por jovens franceses com elevada qualificação e grandes dificuldades de inserção no mercado - com atenção aos casos de desemprego e disposição de relações de trabalho precarizadas - algo semelhante ao que vem acontecendo com os jovens brasileiros nos últimos anos, apesar da expansão do ensino superior (considerando a influência de políticas públicas de acesso e programas de financiamento da educação superior).

Sobretudo, na análise das trajetórias profissionais dos jovens brasileiros não se deve excluir as diferenças sociais imbricadas no processo de inserção, que permeiam não somente as distinções de classe, mas também questões étnicas e de gênero. Além disso, buscar compreender as coletividades que se formam no mercado de trabalho é importante para o entendimento das trajetórias que se constituem para os diversificados grupos juvenis.

Nesse sentido, propõe-se alguns estudos futuros que contemplem análises e reflexões sobre: o processo de inserção profissional de grupos juvenis minoritários, tais como grupos marginalizados, de baixa renda, deficientes e que representam casos de abandono escolar. Estudos que aproximem as vertentes teóricas de inserção profissional (francesa e school-to-work - representativa de países anglo- saxões) e proponham a sua 
integração, pensando em um momento ampliado e que considere as particularidades de cada modelo; como também um mapeamento da realidade laboral dos jovens nas principais metrópoles brasileiras.

\section{REFERÊNCIAS}

ALVES, Natália. Inserção Profissional dos Jovens: do problema social ao objecto sociológico. 2007. Disponível em: <http://www.uff.br/ejatrabalhadores/artigo-02.htm>. Acesso em agosto de 2017.

AMARAL, Marcelo Parreira do; WALTHER, Andreas. Juventude, educação e trabalho: teorizando a regulação de trajetórias educacionais e a transição escola- trabalho. In: MACAMBIRA, Júnior; ANDRADE, Francisca Rejane Bezerra (Orgs.). Trabalho e Formação Profissional: Juventudes em Transição. Fortaleza: IDT, UECE, BNB, 2013, p. $15-35$.

ARRETCHE, Marta. Trajetórias das desigualdades: como o Brasil mudou nos últimos cinquenta anos. 1. ed. São Paulo: Editora Unesp; CEM, 2015.

BALTAR, Paulo. Crescimento da Economia e Mercado de Trabalho no Brasil. In: Presente e Futuro do Desenvolvimento Brasileiro. Editores: André Bojikian Calixtre, André Martins Biancarelli, Marcos Antonio Macedo Cintra. Brasília: IPEA, 2014.

COMIN, Alvaro A. Desenvolvimento econômico e desigualdades no Brasil: 1960- 2010. 2015. In: ARRETCHE, Marta. Trajetórias das desigualdades: como o Brasil mudou nos últimos cinquenta anos. 1. ed. São Paulo: Editora Unesp; CEM, 2015.

CORDEIRO, João Pedro. Modalidades de Inserção Profissional dos Quadros Superiores nas Empresas. Sociologia, Problemas e Práticas, n. ${ }^{\circ}$ 38, 2002, p. 79- 98.

CORROCHANO, Maria Carla. Jovens trabalhadores: expectativas de acesso ao ensino superior. Avaliação (Campinas): Sorocaba, v. 18, n.1, Mar. 2013.

DUBAR, Claude. La construction sociale de l'insertion professionnelle. Éducation et Sociétés. n. 7, 2001/1, p. 23-36.

GALLAND, Olivier. Entrer dans la vie adulte: des étapes toujours plus tardives mais resserrées. Économie et Statistique, n. 337-338, 2000, p. 13-36.

GUIMARÃES, Nadya Araújo. Empresariando o trabalho: os agentes econômicos da intermediação de empregos, esses ilustres desconhecidos. Dados. 2008, vol.51, n.2, p. 275311.

GUIMARÃES, Nadya Araujo; BARONE, Leonardo Sangali; BRITO, Murillo Marschner Alves de. Mercado e mercantilização do trabalho no Brasil (1960-2010). 2015. In: ARRETCHE, Marta. Trajetórias das desigualdades: como o Brasil mudou nos últimos cinquenta anos. 1. ed. São Paulo: Editora Unesp; CEM, 2015.

LEMOS, Ana Heloisa da Costa; DUBEUX, Veranise Jacubowski Correia; PINTO, Mario Couto Soares. Educação, empregabilidade e mobilidade social: convergências e 
divergências. Cadernos EBAPE. BR, v. 7, n. 2, artigo 8, Rio de Janeiro, Jun. 2009, p. 368384.

LEMOS, Ana Heloisa da Costa; NEVES, Diana Rebello; FARIAS RODRIGUES, Patricia dos Reis. Inserção de alunos bolsistas no mercado de trabalho: qual o valor do diploma brasileiro? Revista Pensamento Contemporâneo em Administração, v.7, n.4, p.24-41, 2013

OLIVEIRA, Elenilce Gomes de; SOUSA, Antonia de Abreu. Trabalho, juventude e educação no contexto do capitalismo atual. In: MACAMBIRA, Júnior; ANDRADE, Francisca Rejane Bezerra (Orgs.). Trabalho e Formação Profissional: Juventudes em Transição. Fortaleza: IDT, UECE, BNB, 2013, p. 37-55.

PICCININI, Valmíria Carolina; ROCHA-DE-OLIVEIRA, Sidinei. Inserção profissional: contribuições dos estudos franceses. XXXII Encontro da ANPAD. Rio de Janeiro, Rio de Janeiro, 2008.

ROCHA-DE-OLIVEIRA, Sidinei. Inserção Profissional: Perspectivas Teóricas e Agenda de Pesquisa. Revista Pensamento Contemporâneo em Administração, v.6, n.1, Rio de Janeiro, jan./mar. 2012, 124-135.

ROCHA-DE-OLIVEIRA, Sidinei; PICCININI, Valmíria Carolina. Contribuições das abordagens francesas para o estudo da inserção profissional. Revista Brasileira de Orientação Profissional, Jan./Jun., vol. 13, n. 1, 2012a, p. 63-73.

ROCHA-DE-OLIVEIRA, Sidinei; PICCININI, Valmiria Carolina. Mercado de trabalho: múltiplos (des)entendimentos. Rev. Adm. Pública, vol.45, n.5 pp. 1517-1538, 2011.

ROCHA-DE-OLIVEIRA, Sidinei; PICCININI, Valmíria Carolina. Uma Análise sobre a Inserção Profissional de Estudantes de Administração no Brasil. Revista de Administração Mackenzie, v. 13, n. 2. SÃO PAULO, SP: mar/abr, 2012b, p. 44-75.

SOUZA, Felipe Augusto Silveira de; LEMOS, Ana Heloisa da Costa. Terceirização e resistência no Brasil: o projeto de lei 4.330 e a ação dos atores coletivos. Anais XXXIX Encontro da ANPAD. Belo Horizonte, 2015.

TARTUCE, Gisela. Tensões e intenções na transição escola-trabalho: um estudo das vivências e percepções de jovens sobre os processos de qualificação profissional e (re)inserção no mercado de trabalho na cidade de São Paulo. Tese de doutorado. Universidade de São Paulo: São Paulo, 2007.

VOLKMER MARTINS, Bibiana; ROCHA-DE-OLIVEIRA, Sidinei. A relação entre formação profissional e empregabilidade: em questão os jovens provenientes de cursos superiores de tecnologia. XL Encontro da ANPAD. Costa do Sauipe, Bahia, 2016. 